\title{
Recurrent spinal epidural metastases: a prospective study with a complete follow up
}

\author{
J J van der Sande, W Boogerd, R Kröger, A C Kappelle
}

\begin{abstract}
Objectives-Prospective studies with a complete follow up in patients with spinal epidural metastases (SEM) are rare, so little is known of the incidence and relevance of recurrent spinal epidural metastases (RSEM). This prospective study was undertaken as a part of a previously started and extended prospective study to determine the occurrence and details of RSEM.

Methods-Patients with SEM of various primary malignancies were followed up until death. The diagnosis was confirmed after neurological examination by imaging studies visualising not only the clinically suspected level, but also as much of the spinal canal as possible.

Results-Recurrent spinal epidural metastases (RSEM) occurred in 21 of the 103 patients $(20 \%)$ after a median interval of 7 months and, after treatment, a second recurrence occurred in 11 patients $(11 \%)$, a third recurrence in two patients $(2 \%)$, and a sixth recurrence in one patient (1\%). RSEM developed about as often at the initial level $(55 \%)$ as at a different level $(45 \%)$, did not occur more often in patients with initially multiple SEM, but, not surprisingly, occurred much more often in patients with longer survival. About one half of the patients surviving 2 years, and nearly all patients surviving 3 years or longer developed RSEM. Ambulatory state could be preserved in most patients, even after their second recurrence.

Conclusion-RSEM are common and even several episodes of RSEM in the same patient are not rare. Patients with SEM who survive long enough have a high risk of RSEM and prompt treatment of RSEM to maintain the ambulatory state of the patient is valuable.

(F Neurol Neurosurg Psychiatry 1999;66:623-627)
\end{abstract}

Keywords: spinal cord compression; recurrent spinal epidural metastases; multiple spinal epidural metastases

Table 1 Distribution of primary tumours in patients with spinal epidural metastases

Correspondence to:

Dr JJ van der Sande,

Neurological Division, The

Netherlands Cancer

Institute, Antoni van

Leeuwenhoekziekenhuis,

Plesmanlaan 121, $1066 \mathrm{CX}$

Amsterdam, the Netherlands.

Received 29 September 1998 and in revised form

11 November 1998

Accepted 26 November 1998

\begin{tabular}{llll}
\hline Primary tumour & RSEM & No RSEM & Total \\
\hline Breast & 12 & 44 & 56 \\
Prostate & 2 & 7 & 9 \\
Lymphoma & 1 & 7 & 8 \\
Melanoma & 1 & 5 & 6 \\
Lung & - & 5 & 5 \\
Sarcoma & 1 & 4 & 5 \\
Other & 4 & 10 & 14 \\
Total & 21 & 82 & 103 \\
\hline
\end{tabular}

RSEM: recurrent spinal epidural metastases.
The subject of spinal epidural metastases (SEM) has been discussed increasingly often in the past few decades. Many papers and several reviews emphasised the crucial importance of early diagnosis and prompt treatment to achieve the best possible clinical result, and to keep the patient ambulatory and continent ${ }^{1-11}$. Less attention has been paid to the recurrent SEM (RSEM), ${ }^{212-21}$ complete follow up being exceptional. ${ }^{17}$

This prospective study presents the occurrence and details of RSEM in a group of patients, nearly all of whom were followed up until death.

\section{Patients and methods}

As a part of a previously started and extended prospective study ${ }^{23}$ patients with SEM of various primary malignancies were followed up until death. Patients with known malignant disease who presented with symptoms or signs of radiculopathy or myelopathy underwent imaging studies visualising not only the clinically suspected level, but also as much of the spinal canal as possible. From December 1984 to September 1988 unselected consecutive patients were included whenever the diagnosis SEM was confirmed. As MRI at that time was not yet available, myelography was used, either alone or in combination with CT. Using this imaging procedure the whole spinal canal could be visualised in $17 \%$ of cases, the thoracic and lumbar regions in $67 \%$, the thoracic and cervical regions in $3 \%$, the thoracic region in $3 \%$, the cervical region in $5 \%$, and the lumbar region in $6 \%$. After treatment the patients were followed up by the neurologists (JJvdS, WB) until discontinuation of the steroids and stabilisation of the neurological condition. Subsequently, follow up was performed by the medical oncologist or radiotherapist at intervals of usually 3 months. Again, whenever symptoms or signs of radiculopathy or myelopathy developed, the patient was referred to the neurologist and imaging studies were performed.

\section{Results}

A hundred and three patients (72 women (mean age 55 years), 31 men (mean age 56 years)) were treated for SEM. The primary tumours are presented in table 1.

Twenty four patients (23\%) had multiple SEM, two of whom had a combination of epidural and intradural metastases.

PRIMARY TREATMENT

Primary treatment (table 2) consisted, in the great majority of cases $(90 / 103)$, of radiotherapy, either alone, or in combination with 
Table 2 Treatment of spinal epidural metastases

\begin{tabular}{lllll}
\hline \multicolumn{5}{l}{ Patients who developed RSEM } \\
\cline { 2 - 5 } & $\begin{array}{l}\text { All patients } \\
(n=103)\end{array}$ & $\begin{array}{l}\text { 1st SEM } \\
(n=21)\end{array}$ & $\begin{array}{l}\text { 1st recurrence } \\
(n=21)\end{array}$ & $\begin{array}{l}\text { 2nd recurrence } \\
(n=11)\end{array}$ \\
\hline Radiotherapy $^{\star}$ & 90 & 17 & 12 & 4 \\
Chemotherapy $^{\star}$ & 25 & 4 & 7 & 5 \\
Surgery† & $6 \ddagger$ & $3 \ddagger$ & 4 & 1 \\
Hormonal therapy & 6 & 3 & 2 & 1 \\
Dexamethasone alone & 2 & & & 1 \\
No treatment & 1 & & & \\
\hline
\end{tabular}

SEM = spinal epidural metastasis; RSEM = recurrent spinal epidural metastasis.

*Alone or in combination.

†Anterior spinal body fusion, laminectomy or both.

$\ddagger$ In combination with radiotherapy.

surgery or chemotherapy and/or hormonal therapy. In 10 patients treatment was confined to chemotherapy, hormonal therapy, or both, two patients were treated exclusively with steroids, and in one patient treatment was abandoned. The total dose of radiotherapy varied between 8 and $36 \mathrm{~Gy}$ in one to 10 fractions, according to the primary tumour and to previous treatment. Median radiation dose was 21 Gy in seven fractions. Surgery was performed in cases of vertebral instability, or when the dose of radiotherapy had to be limited because of previous radiotherapy ${ }^{6}$ at the same level for painful vertebral metastases without epidural extension. Usually treatment included temporary administration of dexamethasone in the initial stage.

Thirteen patients $(13 \%)$ were not ambulatory at the moment of diagnosis of SEM, due to neurological deficit. Five patients regained their ambulatory state after treatment. Another five patients $(5 \%)$ had lost their ambulatory state, mainly due to severe pain or skeletal metastases; two became ambulatory again after treatment.

FOLLOW UP

Follow up (table 3) was performed until death in 102 of the 103 patients. One patient with breast cancer is still alive without symptoms and signs, 120 months after treatment for a sacral epidural metastasis and a thoracic vertebral metastasis without epidural extension.

RECURRENT SPINAL EPIDURAL METASTASES

(RSEM)

Recurrent spinal epidural metastases (RSEM) occurred in 21 of the 103 patients (20\%), in 12 of the 56 patients with breast carcinoma $(21 \%)$, and in nine of the 47 patients with other primary tumours (19\%, table 1$)$. RSEM developed after an interval of 1-28 months (median 7 months) after the initial SEM. No RSEM

Table 3 Survival (months) from first occurrence of spinal epidural metastases

\begin{tabular}{|c|c|c|c|c|c|c|}
\hline & \multicolumn{2}{|c|}{ Breast carcinoma } & \multicolumn{2}{|l|}{ Other } & \multicolumn{2}{|l|}{ Total } \\
\hline & $\begin{array}{l}\text { No of } \\
\text { patients }\end{array}$ & $\begin{array}{l}\text { Survival median } \\
-(\text { range) }\end{array}$ & $\begin{array}{l}\text { No of } \\
\text { patients }\end{array}$ & $\begin{array}{l}\text { Survival median } \\
-(\text { range) }\end{array}$ & $\begin{array}{l}\text { No of } \\
\text { patients }\end{array}$ & $\begin{array}{l}\text { Survival median } \\
\text {-(range) }\end{array}$ \\
\hline Total & 56 & $10.5\left(0.5->120^{\star}\right)$ & 47 & $3.5(0.25-49)$ & 103 & $6\left(0.25->120^{\star}\right)$ \\
\hline SSEM & 45 & $9\left(0.5->120^{\star}\right)$ & 34 & $6(0.25-49)$ & 79 & $7\left(0.25->120^{\star}\right)$ \\
\hline MSEM & 11 & $12(0.5-42)$ & 13 & $1(0.5-4)$ & 24 & $3(0.5-42)$ \\
\hline RSEM & 12 & $22(2.5-56)$ & 9 & $20(3.5-49)$ & 21 & $20(2.5-56)$ \\
\hline
\end{tabular}

SSEM = single spinal epidural metastasis; MSEM = multiple spinal epidural metastases; RSEM $=$ recurrent spinal epidural metastasis.

${ }^{\star}$ One patient still alive after follow-up of 120 months.
Table 4 Distribution of spinal epidural metastases in 21 patients with 37 RSEM episodes

\begin{tabular}{lll}
\hline Level & Initial SEM & RSEM \\
\hline Cervical & 2 & 5 \\
Cervicothoracic & - & 2 \\
Thoracic & 13 & 30 \\
Lumbosacral & 8 & 14 \\
Total & 23 & 51
\end{tabular}

developed in the five patients with lung carcinoma, all of whom died within 7 months, median survival being 1 month. Only two of the 24 patients with multiple SEM in the initial stage developed RSEM. These two patients had the longest survival in the group of patients with multiple SEM - of 19 and 42 months respectively - and developed their RSEM after an interval of 10 and 28 months respectively.

Eleven of the 21 patients with RSEM even had more than one episode with recurrence, after varying intervals: nine patients had two episodes with RSEM (four of whom had breast carcinoma), one patient with breast carcinoma had three episodes with RSEM, and one patient with prostate carcinoma had six episodes with RSEM. This resulted in a total of 37 episodes with RSEM. Median interval between first and second RSEM was 4 (range 3/4-44) months.

\section{SITE OF RECURRENCE}

Multiple RSEM in one episode were not uncommon and were found in 11 of the 37 episodes with RSEM in this study. Twenty eight $(55 \%)$ of the total number of 51 RSEM in these 37 episodes occurred at the same level as at a previous examination, 23 (45\%) occurred at a different level. The distribution of the RSEM in comparison with the initial metastases is shown in table 4. First recurrence at the same level occurred after a median interval of 8 (range 12-28) months and at a different level after 6 (range 1-20). months

Seventeen of the 90 patients who received radiotherapy as primary treatment developed RSEM (table 2). Nine of these 17 patients developed RSEM both at the initial and at different levels, five patients developed RSEM only at the initial level, and three patients only at different levels. Radiation dose in the five patients who developed RSEM at the initial level and radiation dose in the three patients who did not, were strikingly similar.

\section{CLINICAL CONDITION OF THE PATIENTS WITH} RSEM

The clinical condition of the patients with RSEM permitted an ambulatory state (table 5) in most patients after their first (initial) and second (first recurrent) episode. Most patients were still ambulatory during their third (second recurrent) episode, although treatment failed in two patients. The patient with six recurrences of epidural metastases maintained the ambulatory state until the sixth recurrence, 6 weeks before his death.

TREATMENT OF THE PATIENTS WITH RSEM Treatment of the patients with RSEM (table 2) consisted mainly of radiotherapy, chemo- 
Table 5 Ambulatory state in the various episodes of the 21 patients who developed RSEM

\begin{tabular}{|c|c|c|c|c|c|c|c|}
\hline & \multicolumn{7}{|l|}{ Episodes } \\
\hline & First $n=21$ & $\begin{array}{l}\text { Second } \\
(=1 \text { st } R S E M) \\
n=21\end{array}$ & $\begin{array}{l}\text { Third } \\
(=2 n d \text { RSEM) } \\
n=11\end{array}$ & $\begin{array}{l}\text { Fourth } \\
(=3 r d \text { RSEM) } \\
n=2\end{array}$ & $\begin{array}{l}\text { Fifth } \\
(=4 \text { th RSEM) } \\
n=1\end{array}$ & $\begin{array}{l}\text { Sixth } \\
(=5 \text { th RSEM) } \\
n=1\end{array}$ & $\begin{array}{l}\text { Seventh } \\
(=6 \text { th RSEM) } \\
n=1\end{array}$ \\
\hline Ambulatory & 17 & 18 & $9^{\star \star \star}$ & 1 & 1 & 1 & 0 \\
\hline Not ambulatory & $4^{\star}$ & $3 \star \star$ & 2 & 1 & 0 & 0 & 1 \\
\hline
\end{tabular}

Table 6 Proportion RSEM/no RSEM (patients) and survival

\begin{tabular}{llll}
\hline Survival $(y)$ & $\begin{array}{l}\text { Breast cancer } \\
n=56\end{array}$ & Other $n=47$ & Total $n=103$ \\
\hline 0.5 & $10 / 24$ & $6 / 8$ & $16 / 32$ \\
1 & $9 / 14$ & $5 / 3$ & $14 / 17$ \\
1.5 & $8 / 11$ & $5 / 2$ & $13 / 13$ \\
2 & $6 / 6$ & $3 / 2$ & $9 / 8$ \\
3 & $3 / 1$ & $2 / 0$ & $5 / 1$ \\
4 & $2 / 1$ & $1 / 0$ & $3 / 1$ \\
$5-9 \star$ & $0 / 1$ & - & $0 / 1$ \\
\hline
\end{tabular}

*Still alive after 120 months, without recurrence

therapy becoming relatively more important for the treatment of recurrent tumour at the original site.

SURVIVAL

Survival of the whole group of 102 patients who were followed up until death (table 3) ranged from 1 week to 56 months (median 6 months). Patients with SEM from breast carcinoma survived longer than patients with SEM from other primary tumours, median survival being 10.5 v 3.5 months. Patients with multiple SEM, but not from breast carcinoma, tended to have a shorter survival than patients with single SEM (median survival 3 months $v 7$ months). Patients with RSEM, both from breast carcinoma and from other primary tumours survived longer, median survival being 22 and 18.5 months, respectively. Median survival after the last recurrence was 2.5 (range 0.5-27) months. Median survival after the first episode was longer in patients with multiple recurrent episodes: 18 months in the 10 patients with one recurrent episode, 22 months in the eight patients with two recurrent episodes; survival was 33 months in the patient with three recurrent episodes and 38 months in the patient with six recurrent episodes. The relation between the duration of survival and the occurrence of RSEM is presented in table 6: RSEM occurred in one third of the total number of patients surviving 6 months, in slightly less than one half of the patients surviving 1 year, in slightly more than one half of the patients surviving 2 years, and in most patients surviving 3 or more years.

\section{Discussion}

Recurrent spinal epidural metastases are not uncommon. In the present study RSEM occurred in $19 \%$ of the patients with spinal epidural metastases, slightly more often in the patients with breast cancer $(21 \%)$ than in the patients with other primary tumours (17\%). In the literature the second occurrence of SEM has received little attention, and usually has been mentioned only occasionally.

Gilbert $e t a l,{ }^{2}$ when presenting their results of treatment of SEM, reported a relapse rate in less than 6 months of $22 \%$ of the 170 patients in their group treated with radiotherapy, and in $25 \%$ of the 65 patients in their surgically treated group; about one half of the patients in both groups remained ambulatory for at least 1 year. No further details about RSEM were given. Greenberg et $a l^{12}$ analysed long term follow up from the series reported by Gilbert et al, and found three patients with recompression of the 19 patients who were ambulatory at 1 year. Recompression occurred after 16, 36, and 48 months respectively. Nine patients were still alive at the moment of analysis. Loeffler $e t a l^{13}$ reported RSEM in $11 \%$ of their 80 patients within the original treatment field, and in $26 \%$ elsewhere in the spinal canal. Nearly one half of the RSEM occurred within 1 week, and could be considered as "skipped lesions" at the time of diagnosis.

Rodichok et $a l^{14}$ found progression of a previously treated epidural metastasis in $9 \%$, and a new epidural metastasis in $7 \%$ of their 71 evaluable patients.

Maranzano et $a l^{15}$ analysed prospectively 105 consecutive patients with metastatic spinal cord compression and reported a median survival time of 7 months, and a median duration of improvement after treatment of 8 months, but did not mention patients with RSEM.

Smith et $a l^{20}$ and Huddart et $a l^{1}$ studied patients with prostate carcinoma and found RSEM in respectively seven out of $26(27 \%)$ and 13 out of $69(19 \%)$ patients. In the study of Smith et al three patients (43\%) had RSEM within a previous radiation port, whereas four (57\%) developed RSEM at a different level.

Only two studies presented RSEM in more detail: Kaminski et $a l^{16}$ reviewed the records of 79 men with spinal epidural metastases, most of whom had prostate cancer, and found RSEM in $16 \%$. Mean interval between the moment of diagnosis of the first epidural metastasis and of the RSEM was 2.8 months in cases of RSEM within two vertebral bodies, and 15.2 months in cases of RSEM at three or more vertebral bodies from the prior lesion.

Helweg-Larsen et al, ${ }^{17}$ following up their 107 patients until death, reported RSEM in eight of $107(7,5 \%)$ patients with spinal epidural metastases from various primary malignancies. The initial SEM were treated with radio- 
therapy (28 Gy, given in seven fractions of 4 Gy). All RSEM occurred in a new location in the spinal canal. RSEM occurred with the same frequency in patients with single as in patients with multiple epidural metastases, and RSEM did not occur significantly more often in patients who had not received local treatment for asymptomatic epidural metastases. Patients with RSEM survived longer, and the authors concluded that the duration of survival might have been the main determining factor for the risk of RSEM. More recently, in a larger series of patients with a less complete follow up, the same author observed RSEM in 14 of 153 patients $(9 \%) .^{18}$

The higher frequency of RSEM in the present study $(20 \%)$, might be explained for several reasons. A difference in distribution of the primary tumour, more breast carcinoma, and less lung and prostate carcinoma in the present study in comparison with the HelwegLarsen study, may be important. However, in our study RSEM from breast carcinoma did not occur much more often than RSEM from other tumours. Another difference between the two studies is the difference in clinical condition: $45 \%$ of the patients were not ambulatory at the time of diagnosis in the HelwegLarsen study versus $18 \%$ in the present study. Possibly referral to the neurological department occurred earlier in the present study, which may be related with a longer median survival ( 6 ข 3.4 months). In both studies longer survival was associated with an increased risk of RSEM, and in the present study nearly all patients surviving 3 years or longer had RSEM. This increased risk of RSEM in patients with longer survival was also reported by Huddart et $\mathrm{al}^{21}$ in their study of patients with prostate carcinoma: $50 \%$ at 3 years, and $75 \%$ at 5 years.

Finally the use of a relatively low dose of radiotherapy in the present study might be a reason for the high frequency of RSEM: 55\% of RSEM occurred at the same level as at a previous examination. Possibly, a higher radiation dose would have resulted in a lower frequency of RSEM. However, even if radiotherapy would have prevented all RSEM at the same level, 12 patients who received radiotherapy as primary treatment, and four patients who had chemotherapy or hormonal therapy as primary treatment, would have developed RSEM at a different level. The frequency of RSEM in the whole group of patients would have been $15.5 \%$ ( 16 of 103 patients) instead of $20 \%$ (21 of 103 patients). It may be concluded that the optimal result of radiotherapy could be a considerable reduction of RSEM but a much smaller reduction of patients with RSEM.

In this respect it is worthy of note that (1) Huddart $e t a l,{ }^{21}$ in their study of patients with prostate carcinoma, found no significant difference in the rate of RSEM at the initial site after a radiation dose of $30 \mathrm{~Gy}$ or less and a radiation dose of more than $30 \mathrm{~Gy}$, and (2) in the present study radiation dose in the patients who developed RSEM only at the initial level, and radiation dose in the patients who developed RSEM only at a different level, were strikingly similar.

Third or more episodes of SEM are hardly ever reported: Kaminski et $a l^{16}$ report one of their 13 patients with RSEM as having a third epidural metastasis of a prostate carcinoma, at the same level as the initial metastasis. HelwegLarsen et $a l,{ }^{17}$ although following up their patients until death, do not mention third occurrences of SEM. The findings of the present study, a third occurrence in one half of the patients with a second occurrence-that is, $11 \%$ of the whole group of 103 patientsconfirms the importance of continuing neurological observation of patients with SEM, most of whom will remain ambulant after repeated and timely treatment. At the first occurrence of SEM radiotherapy is usually the treatment of choice, but, although reirradiation has been shown to be an efficacious treatment, ${ }^{19}$ at second and third occurrence other treatment modalities, such as surgery ${ }^{64}$ and chemotherapy may become more important, particularly when radiotherapy has been administered extensively at the same level.

Multiple RSEM occurred in nearly one third of the episodes (11/37) - that is, with the same frequency as multiple SEM in the initial episode in a previous study. ${ }^{22}$ Accordingly, it should be recommended that as much spinal canal as possible is visualised, not only in case of the first occurrence of SEM, but also in cases of recurrent SEM.

Both patients and doctors should be prepared to encounter symptoms and signs of RSEM, diagnosis should be as extensive and early as during the first occurrence of SEM, and prompt treatment is important to maintain an acceptable quality of life.

1 Törma T. Malignant tumours of the spine and the spinal extradural space. A study based on 250 histologically verified cases. Acta Chir Scand (Suppl) 1957;225:1-176.

2 Gilbert RW, Kim JH, Posner JB. Epidural spinal cord compression from metastatic tumor: diagnosis and treatment. Ann Neurol 1978;3:40-51.

3 Black P. Spinal metastasis, current status and recommended Black P. Spinal metastasis, current status and recommended
guidelines for management. Neurosurgery 1979;5:726-46. guidelines for management. Neurosurgery 1979;5:726-46.
Stark RJ, Henson RA, Evans SJW. Spinal metastases: a retStark RJ, Henson RA, Evans SJW. Spinal metastases: a ret-
rospective survey from a general hospital. Brain 1982;105: 189-213.

5 Barcena A, Lobato RD, Rivas JJ, et al. Spinal metastatic disease: analysis of factors determining functional prognosis and the choice of treatment. Neurosurgery 1984;15:820-

6 Siegal T, Siegal T. Surgical decompression of anterior and posterior malignant epidural tumors compressing the spinal cord: a prospective study. Neurosurgery 1985;17:42432.

7 Byrne TN, Waxman SG. Spinal cord compression: diagnosis and principles of treatment. Contemporary neurology series. Vol

8 Grant R, Papadopoulos SM, Greenberg HS. Metastatic epidural spinal cord compression. Neurol Clin 1991;9:825-41.

9 Ratanatharathorn V, Powers WE. Epidural spinal cord compression from metastatic tumor: diagnosis and guidelines for management. Cancer Treat Rev 1991;18:55-71.

10 Byrne TN. Spinal cord compression from epidural metastases. N Engl f Med 1992;327:614-19.

11 Boogerd W, van der Sande JJ. Diagnosis and treatment of spinal cord compression in malignant disease. Cancer Treat Rev 1993;19:129-50.

12 Greenberg HS, Kim JH, Posner JB. Epidural spinal cord compression from metastatic tumor: results with a new treatment protocol. Ann Neurol 1980;8:361-6.

13 Loeffler JS, Glicksman AS, Tefft M, et al. Treatment of spinal cord compression: a retrospective analysis. Med Pediatr Oncol 1983;11:347-51.

14 Rodichok LD, Ruckdeschel JC, Harper GR, et al. Early detection and treatment of spinal epidural metastases: the role of myelography. Ann Neurol 1986;20:696-702. 
15 Maranzano E, Latini $\mathrm{P}$, Checcaglini $\mathrm{F}$, et al. Radiation therapy in metastatic spinal cord compression. A prospec-
tive analysis of 105 consecutive patients. Cancer 1991;67: tive analysis $1311-17$.

16 Kaminski HJ, Diwan VG, Ruff RL. Second occurrence of spinal epidural metastases. Neurology 1991;41:744-6.

17 Helweg-Larsen S, Hansen SW, Sörensen PS. Second occurrence of symptomatic metastatic spinal cord compression and findings of multiple spinal epidural metastases. Int $\mathcal{f}$ Radiation Oncology Biol Phys 1995;33:595-8.

18 Helweg-Larsen S. Clinical outcome of metastatic spinal cord compression. A prospective study of 153 patients. Acta Neurol Scand 1996;94:269-75.

19 Schiff D, Shaw EG, Cascino TL. Outcome after spinal reirradiation for malignant epidural spinal cord compression. Ann Neurol 1995;37:583-9.
20 Smith EM, Hampel N, Ruff RL, et al. Spinal cord compression secondary to prostate carcinoma: treatment and prog993;149:330-3.

21 Huddart RA, Rajan B, Law $\mathrm{M}$, et al. Spinal cord compression in prostate cancer: treatment outcome and prognostic factors. Radiother Oncol 1997;44:229-36.

22 Van der Sande JJ, Kröger R, Boogerd W. Multiple spinal pidural metastases; an unexpectedly frequent finding. $\mathcal{F}$ Neurol Neurosurg Psychiatry 1990;53:1001-3.

23 Boogerd W, van der Sande JJ, Kröger R. Early diagnosis and treatment of spinal epidural metastasis in breast cancer: a prospective

24 Sundaresan N, Steinberger AA, Moore F, et al. Indications and results of combined anterior-posterior approaches for spine tumor surgery. $\mathcal{F}$ Neurosurg 1996;85:438-46. 